\title{
Effect of $\mathrm{BaFe}_{12} \mathrm{O}_{19}$ Nanoparticles Addition on (Bi,Pb)-2223 Superconducting Phase
}

\author{
Khulud Habanjar' ${ }^{1}$, F. El Haj Hassan² \& R. Awad ${ }^{1}$ \\ ${ }^{1}$ Physics Department, Beirut Arab University, Beirut, Lebanon \\ ${ }^{2}$ Research Platform for Environmental Sciences (PRASE)-DSST, Lebanese University, Beirut, Lebanon \\ Correspondence: Khulud Habanjar, Physics Department, Beirut Arab University, Beirut, Lebanon. E-mail: \\ khulud_h@live.com
}

Received: February 4, 2019

Accepted: March 10, 2019

Online Published: March 20, 2019

doi:10.5539/mas.v13n4p61

URL: https://doi.org/10.5539/mas.v13n4p61

\begin{abstract}
The aim of this work is to investigate the effect of $\mathrm{BaFe}_{12} \mathrm{O}_{19}$ nanoparticles on the microstructure, phase formation and mechanical properties of $(\mathrm{Bi}, \mathrm{Pb})-2223$ superconducting phase. Co-precipitation and solid-state reaction techniques were used to synthesize $\mathrm{BaFe}_{12} \mathrm{O}_{19}$ nanoparticles and $\left(\mathrm{BaFe}_{12} \mathrm{O}_{19}\right)_{\mathrm{x}}(\mathrm{Bi}, \mathrm{Pb})-2223$ superconducting samples with $0.00 \leq \mathrm{x}(\mathrm{wt} \%) \leq 1.5$, respectively. $\mathrm{BaFe}_{12} \mathrm{O}_{19}$ nanoparticles and $\left(\mathrm{BaFe}_{12} \mathrm{O}_{19}\right)_{\mathrm{x}}(\mathrm{Bi}, \mathrm{Pb})-2223$ structures were performed using $\mathrm{X}$-ray diffraction. The morphology of $\mathrm{BaFe}_{12} \mathrm{O}_{19}$ nanoparticles and $\left(\mathrm{BaFe}_{12} \mathrm{O}_{19}\right)_{\mathrm{x}}(\mathrm{Bi}, \mathrm{Pb})-2223$ were observed by means of transmission electron microscope (TEM) and scanning electron microscope (SEM), respectively. The experimental results reveal the composition of Bi-2223 phase and traces of Bi-2212 as a secondary phase when compared to the undadded sample. Lattice parameters are not altered with $\mathrm{BaFe}_{12} \mathrm{O}_{19}$ addition which indicate that nanoparticles do not enter the host crystal of $(\mathrm{Bi}, \mathrm{Pb})-2223$. Vickers microhardness $\mathrm{H}_{\mathrm{v}}$ is measured as function of indentation load and time. It was found that microhardness has a nonlinear trend with applied load and time. The experimental results were analyzed using different models. The analysis revealed that the HK model was more suitable than the other approaches in estimating the load independent hardness of the samples.
\end{abstract}

Keywords: $\mathrm{BaFe}_{12} \mathrm{O}_{19}$ nanoparticles, $(\mathrm{Bi}, \mathrm{Pb})-2223$ superconductor, creep indentation, Vickers microhardness

\section{Introduction}

$\mathrm{Bi}_{2} \mathrm{Sr}_{2} \mathrm{Ca}_{n-1} \mathrm{Cu}_{n} \mathrm{O}_{2 n+4+y}$ ceramic superconductor ( $\mathrm{n}=1,2$ and 3 ) BSCCO, being characterized by its high superconducting transition temperature $T_{c}$ and high critical current density $J_{c}$, is considered as an interesting material for technological applications (Celebi, Karaca, Ozturk, \& Nezir, 1998) (Khalil, 2006). On the other hand, BSCCO is often characterized by its poor mechanical performance; low ductility and elevated brittleness (voids, microcraks, grain and twin boundaries, nonstoichiometric oxygen content) (Karaca, Uzun, Kolemen, Yilmaz, \& Sahin, 2009).

For most applications, such materials take the form of wires and tapes. When making coils, materials are subjected to mechanical stresses; Lorentz force generates cracks, which cause the destruction of the material under high currents. Therefore, the investigation and the improvement of the mechanical properties of these materials is a critical issue for their practical applications. Ishizuka et al [Ishizuka, \& Sakabura 2006] investigated the mechanical strength of bulk Bi-2223 phase. It was found that, Bi-2223 is suitable for cryocooler-cooled superconducting magnets. Konishi et al (Konishi, Takamura, Kaga, \& Katsuse, 1989) proposed the alginate method for the fabrication of superconducting oxide ceramic fibers. Y-Ba-Cu-O superconducting fibers have shown a tensile strength of $192 \mathrm{MPa}$ and an end-point $\mathrm{T}_{\mathrm{c}}$ of $85 \mathrm{~K}$. Li et al (Li, Gao, Cooper, Liu, \& Dou, 2001) investigated the effects of mechanical deformation on the kinetics of the Bi-2212 to Bi-2223 phase transformation. It was shown that the increase in the mechanical deformation provides high internal energy, which enhances the formation of Bi-2223 phase.

Microhardness is the mechanical property describing the material's resistance to deformation upon indentation. It is considered to be an effective tool to get into the material composition and structure (Kolemen, Uzun, Yilmazlar, Guclu, \& Yanmaz 2006)(Guilmeau, Andrzejewski, \& Noudem, 2003)(Yilmazlar, Centinkara, Nursoy, Ozturk, \& Terzioglu, 2006)(Jia et al, 2000)(Haugan et al, 2000)(Sengupta et al, 1996) (Kazin, Jansen, Larrea, De la funette, 
\& Tretyakov, 1995). One of the most practical technique for enhancing the microhardness of superconducting phases is the filling of voids by addition/substitution of nanoparticles. (Karara, Uzun, Kolemen, Yilmaz, \& Sahin 2009)(Abdeen, et al, 2016)(Awad, 2008)(Mohammed, Abou Aly, Ibrahim, Awad , \& Rekaby, 2011)(Aydin, Cakiroglu, Nursoy, \& Terzioglu, 2009)(Terzioglu, 2011). The introducing of $\mathrm{ZnO}$ in $\mathrm{Bi}_{1.84} \mathrm{~Pb}_{0.34} \mathrm{Sr}_{1.91} \mathrm{Ca}_{2.03} \mathrm{Cu}_{3.06} \mathrm{O}_{10}$ superconductors increased the indentation hardness and the elastic modulus values as observed by Karaca et al (Karaca, Uzun, Kolemen, Yilmaz, \& Sahin, 2009). Abdeen et al (Abdeen et al, 2016) showed that the substitution of 0.025 of holmium increased the Vickers microhardness of $(\mathrm{Bi}, \mathrm{Pb})-2223$ superconducting phase and it had a normal indentation behavior. Awad (Awad, 2008) found that $0.6 \mathrm{wt} \% \mathrm{of} \mathrm{MgO}$ addition enhanced Vickers microhardness of $\left(\mathrm{Cu}_{0.25} \mathrm{Tl}_{0.75}\right)$-1234. Mohammed et al (Mohammed, Abou Aly, Ibrahim, Awad, \& Rekaby, 2011) showed that the mechanical parameters depend on $\mathrm{SnO}_{2}$ and $\mathrm{In}_{2} \mathrm{O}_{3}$ 's additions.

The aim of this work is the enhancement of the mechanical properties, through Vickers microhardness meassurements, by the addition $(\mathrm{x})$ of $\mathrm{BaFe}_{12} \mathrm{O}_{19}$ nanoparticles to $(\mathrm{Bi}, \mathrm{Pb})-2223$ superconducting ceramics. Additionally, the effect of $\mathrm{BaFe}_{12} \mathrm{O}_{19}$ on the structure and composition of the main phase was investigated by means of X-ray diffraction (XRD) and scanning electron microscope (SEM) analysis used to characterize the microstructures of the sample phases.

\section{Method}

\subsection{Synthesis and Preparation}

\subsubsection{Synthesis of $\mathrm{BaFe}_{12} \mathrm{O}_{19}$ Nanoparticles by Co-Precipitation Technique}

An aqueous solution of PVP (MW=29000) was prepared by dissolving $4 \mathrm{~g}$ of this polymer in $100 \mathrm{~mL}$ distilled water and heating at $80^{\circ} \mathrm{C}$ for 15 minutes. Iron (III) Chloride Hexahydrate $\left(\mathrm{FeCl}_{3} \cdot 6 \mathrm{H}_{2} \mathrm{O}\right)$ and Barium Chloride Dehydrate $\left(\mathrm{BaCl}_{2} .2 \mathrm{H}_{2} \mathrm{O}\right)$ solutions were prepared in distilled water and mixed together with the PVP solution. 4M of $\mathrm{NaOH}$ solution was added dropwise to the solution to adjust its $\mathrm{pH}$ to 12 . After fixing the $\mathrm{pH}$ at a highly basic condition $(\mathrm{pH} \approx 12)$ which is convenient for the direct preparation of $\mathrm{BaFe}_{12} \mathrm{O}_{19}$ crystals, the reaction was stirred for $2 \mathrm{~h}$ at $60^{\circ} \mathrm{C}$. The resultant brown precipitate was washed continuously with distilled water to remove the residues, until the $\mathrm{pH}$ is 7 . After drying the sample at $100^{\circ} \mathrm{C}$ for 18 hours, the ingots were then calcinated at 950 ${ }^{\circ} \mathrm{C}$ for 2 hours.

\subsubsection{Synthesis of $\left(\mathrm{BaFe}_{12} \mathrm{O}_{19}\right)_{x}(\mathrm{Bi}, \mathrm{Pb})-2223$ superconducting Samples by Co-Precipitation Technique}

Solid-state reaction technique was used to synthesize bismuth-based superconducting samples with chemical formula $\left(\mathrm{BaFe}_{12} \mathrm{O}_{19}\right)_{\mathrm{x}}\left(\mathrm{Bi}_{1 \cdot 6} \mathrm{~Pb}_{0.4}\right) \mathrm{Sr}_{2} \mathrm{Ca}_{2} \mathrm{Cu}_{3} \mathrm{O}_{10-\delta},\left(\mathrm{BaFe}_{12} \mathrm{O}_{19}\right)_{\mathrm{x}}(\mathrm{Bi}, \mathrm{Pb})-2223,0.00 \leq \mathrm{x}(\mathrm{wt} \%) \leq 1.5$. High purity of $\mathrm{Bi}_{2} \mathrm{O}_{3}, \mathrm{PbO}, \mathrm{PbO}_{2}, \mathrm{SrCO}_{2}, \mathrm{CuO}$ and $\mathrm{CaO}$ with stoichiometric amounts were mixed and grinded in an agate mortar to get an homogenous mixture and then sifted using $50 \mu \mathrm{m}$ sieve. The obtained mixture was heated at $820^{\circ} \mathrm{C}$ for 48 hours with an intermediate grinding process. After that, the obtained black powder is pressed under a hydraulic press to 5 tons $/ \mathrm{cm}^{2}$ into pellets of diameter $1.5 \mathrm{~cm}$. The pellets are then heated with a heating rate of 4 ${ }^{\circ} \mathrm{C} / \mathrm{min}$ at $845^{\circ} \mathrm{C}$ for 96 hours and then cooled at a rate of $2{ }^{\circ} \mathrm{C} / \mathrm{min}$. $\mathrm{BaFe}_{12} \mathrm{O}_{19}$ nanoparticles were added at the final step and the mixture which was pressed and heated again with a rate of $2{ }^{\circ} \mathrm{C} / \mathrm{min}$ at $845^{\circ} \mathrm{C}$ for 48 hours and then cooled at a rate of $1{ }^{\circ} \mathrm{C} / \mathrm{min}$.

\subsection{Characterization of the Samples}

\subsubsection{Structure and Morphology}

The structural features of $\mathrm{BaFe}_{12} \mathrm{O}_{19}$ nanoparticles and $\left(\mathrm{BaFe}_{12} \mathrm{O}_{19}\right)_{\mathrm{x}}(\mathrm{Bi}, \mathrm{Pb})-2223$ superconducting samples were investigated using X-ray diffraction (XRD) analysis using the Bruker D8 advance powder diffractometer. The $\mathrm{XRD}$ technique has been used to estimate the phase composition of the superconducting system. The relative volume fractions of the main phase $(\mathrm{Bi}, \mathrm{Pb})-2223$ was determined from the obtained peak intensities, using the following well-known expressions (Halim, Khawaldeh, Mohammed, \& Azhan, 1999):

$$
(B i, P b)-2223 p)=\frac{\sum I_{B i-2223}}{\sum I_{B i-2223}+\sum I_{B i-2212}+\sum I_{\mathrm{Ca}_{2} P b O_{4}}},
$$

Transmission electron microscope (TEM) (JEOL JEM 100Cx microscope) and scanning electron microscope (JEOL JSM), were used for the analysis of the microstructure morphologies of $\mathrm{BaFe}_{12} \mathrm{O}_{19}$ nanoparticles and $\left(\mathrm{BaFe}_{12} \mathrm{O}_{19}\right)_{x}(\mathrm{Bi}, \mathrm{Pb})-2223$ superconducting samples, respectively.

\subsubsection{Vickers Microhardness}

Room temperature Vickers microhardness of $\left(\mathrm{BaFe}_{12} \mathrm{O}_{19}\right)_{\times}(\mathrm{Bi}, \mathrm{Pb})-2223$ superconducting samples was performed 
by means of digital microhardness tester (MHVD-1000IS). The pyramidal indentation loads varied from $0.49 \mathrm{~N}$ up to $9.8 \mathrm{~N}$ with dwell indentation time varying from 5 up to $60 \mathrm{sec}$. Indentations were made at different parts of the samples' surface. An average of 5 readings at different locations of the specimen surfaces was taken to obtain reasonable mean values for each load. The apparent value of Vickers microhardness was estimated from the following equation:

$$
H_{v}=1854.4 \times \frac{F}{d^{2}} ?(G P a)
$$

where $F$ is the applied load in $N$ and $d$ is the diagonal length of the indentation in micrometers.

\section{Results}

\subsection{Sample Investigation}

Figure 1 shows room temperature XRD patterns for $\mathrm{BaFe}_{12} \mathrm{O}_{19}$ nanoparticles. The observed peaks are well indexed by the hexagonal indices $\mathrm{BaFe}_{12} \mathrm{O}_{19}$ with space group P63/mmc. Similar results were obtained by Ding et. al. reported from Mössbauer spectra (Ding, Yang, Miao, McCormick, \& Street, 1995). The morphology of $\mathrm{BaFe}_{12} \mathrm{O}_{19}$ nanoparticles was examined using TEM technique in Figure 2. It is clear from the micrograph that the sample is mainly composed of rod-like nanoparticles together with a hexagonal shape oriented particles. Similar rod-like particles were observed for Barium hexaferrite by Ohlan et. al. (Ohlan, Singh, Chandra, \& Dhawan, 2008).
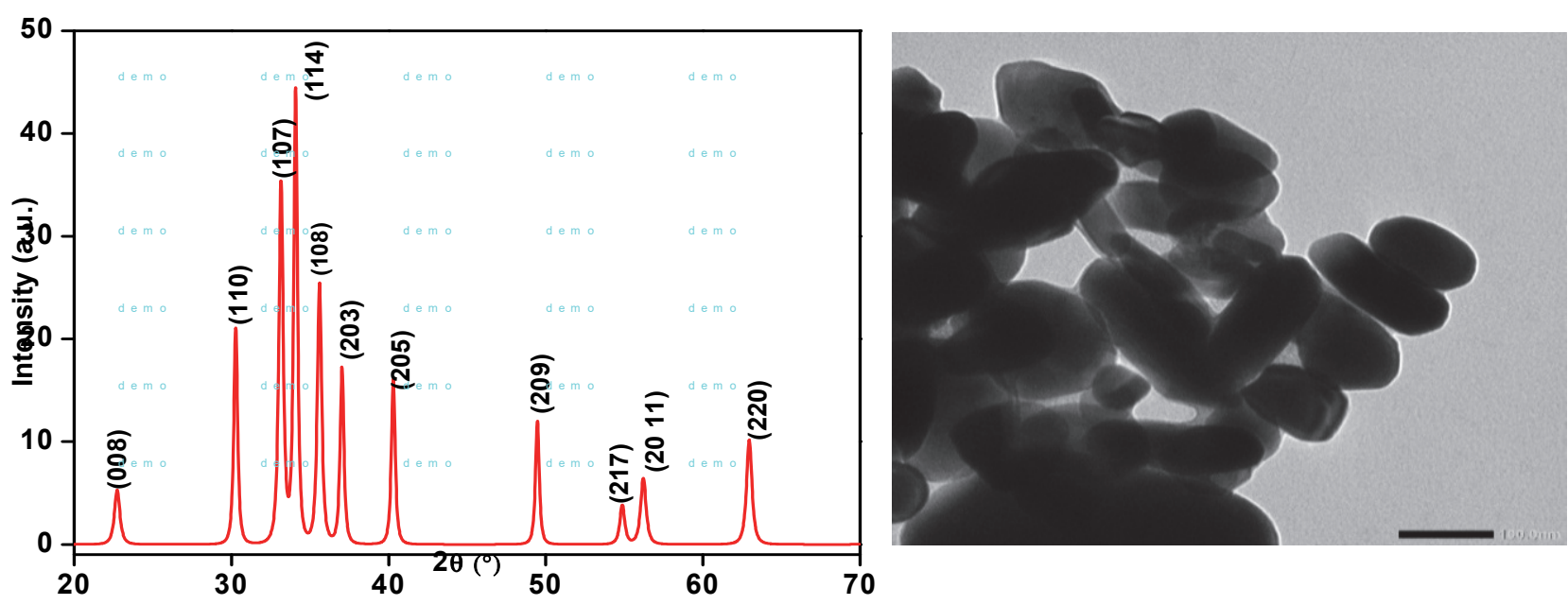

Figure 1. XRD patterns of $\mathrm{BaFe}_{12} \mathrm{O}_{19}$ nanoparticles

Figure 2. TEM micrograph of $\mathrm{BaFe}_{12} \mathrm{O}_{19}$

Crystallite size (D) is calculated from XRD by using Scherrer's equation:

$$
D=\frac{\mathrm{k} \lambda}{\beta \cos \theta}
$$

where $\lambda$ is the $\mathrm{X}$-ray wavelength, $\beta$ is the full width at half maxima (in radian), $\theta$ is the Bragg angle and $\mathrm{k}$ is the hexagonal structure's shape factor equals to 1 . The lattice parameters a and c as well as the crystallite size (D) are listed in Table (1).

Table 1. Lattice parameters and crystal size for BaFe12O19 nanoparticles

\begin{tabular}{lccc}
\hline \multicolumn{2}{c}{$\mathrm{BaFe}_{12} \mathrm{O}_{19}$ nanoparticles } \\
\hline $\begin{array}{l}\text { Lattice } \\
\text { XRD }\end{array}$ & \multicolumn{2}{c}{ parameters } & TEM \\
\hline $\mathrm{a}(\AA)$ & $\mathrm{c}(\AA)$ & $\mathrm{D}(\mathrm{nm})$ & $\mathrm{D}(\mathrm{nm})$ \\
\hline 5.879 & 3.130 & 67.723 & 62.60 \\
\hline
\end{tabular}


XRD pattern for $\left(\mathrm{BaFe}_{12} \mathrm{O}_{19}\right)_{\mathrm{x}}(\mathrm{Bi}, \mathrm{Pb})-2223$ samples is shown in Figure 3. The tetragonal structure of $(\mathrm{Bi}, \mathrm{Pb})-2223$ superconducting phase with space group $\mathrm{P} 4 / \mathrm{mmm}$ is dominant for all samples. Minor peaks of $(\mathrm{Bi}, \mathrm{Pb})-2212$ and $\mathrm{Ca}_{2} \mathrm{PbO}_{4}$ appear as secondary phases. Lattice parameters a and $\mathrm{c}$ as well as the volume fraction of the host $(\mathrm{Bi}, \mathrm{Pb})-$ 2223 were determined and listed in Table 2. It is clear that the lattice parameters have no significant change with the addition of $\mathrm{BaFe}_{12} \mathrm{O}_{19}$ nanoparticles. Therefore, nanoparticles do not enter the crystal; they are settled at the grain boundaries.

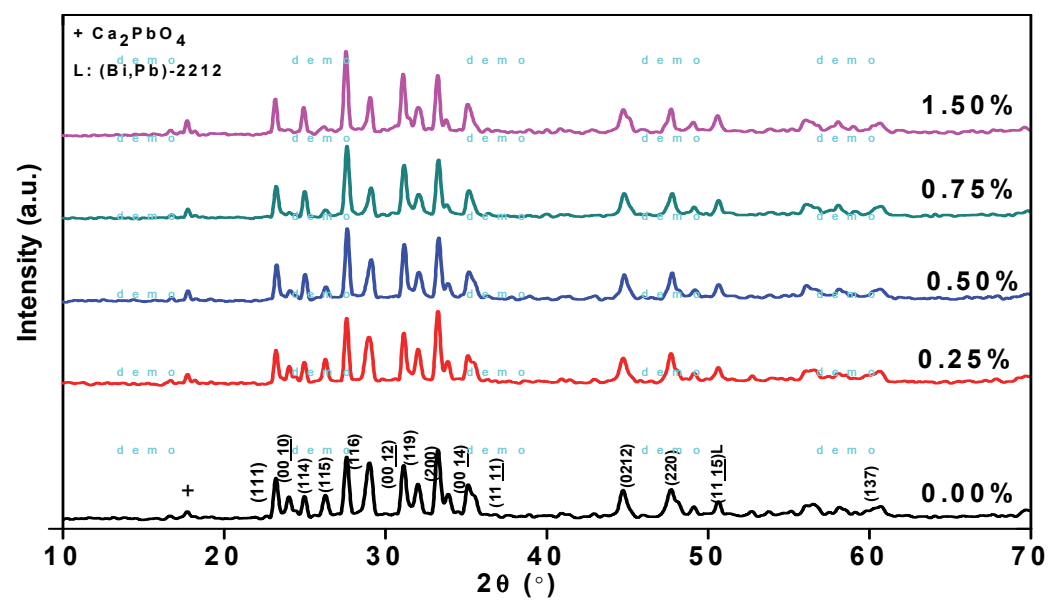

Figure 3. XRD patterns for $\left.\left(\mathrm{BaFe}_{12} \mathrm{O}_{19}\right)_{\mathrm{x}} \mathrm{Bi}, \mathrm{Pb}\right)-2223$ superconducting samples

The volume fraction of the main (Bi,Pb)-2223 phase increases up to an addition of $0.5 \mathrm{wt} \%$ of BaFe12O19 above which it starts to decrease. Similar results were observed by Kong et. al. [Kong, \& Abd-Shukor, 2010] for studying the effect of $\mathrm{NiFe} 2 \mathrm{O} 4$ nanoparticles addition into $\mathrm{Bi} 1.8 \mathrm{~Pb} 0.4 \mathrm{Sr} 2 \mathrm{Ca} 2 \mathrm{Cu} 3 \mathrm{O} 10+\delta$ phase.

Table 2. Lattice parameters and volume fraction for $(\mathrm{BaFe} 12 \mathrm{O} 19) \mathrm{x}(\mathrm{Bi}, \mathrm{Pb})-2223$ superconducting samples

\begin{tabular}{cccc}
\hline \multicolumn{4}{c}{$\left(\mathrm{BaFe}_{12} \mathrm{O}_{19}\right)_{\mathrm{x}}(\mathrm{Bi}, \mathrm{Pb})-2223$} \\
\hline $\mathrm{x}(\mathrm{wt} \%)$ & $\mathrm{a}(\AA)$ & $\mathrm{c}(\AA)$ & Volume fraction \\
\hline 0.00 & 5.372 & 37.021 & $(\mathrm{Bi}, \mathrm{Pb})-2223(\%)$ \\
0.25 & 5.374 & 37.016 & 94.18 \\
0.5 & 5.371 & 37.01 & 95.23 \\
0.75 & 5.374 & 37.018 & 97.26 \\
1.5 & 5.372 & 37.02 & 96.39 \\
\hline
\end{tabular}

The surface morphology of $(\mathrm{BaFe} 12 \mathrm{O} 19) \mathrm{x}(\mathrm{Bi}, \mathrm{Pb})-2223$ samples, for $\mathrm{x}=0.00(\mathrm{a}), \mathrm{x}=0.5 \%$ (b) and $1.5 \%(\mathrm{c})$, are shown in Figure 4. It is clear that, with the addition of nanoparticles, the pure sample changes its morphology from flaky layers of large randomly distributed platelet into better texturing and growth in Figure 4(b). A degradation of the grain connectivity is observed with an increase in the grain and the appearance of voids with further increase of nanoparticles addition as it is clear in Figure 4(c).
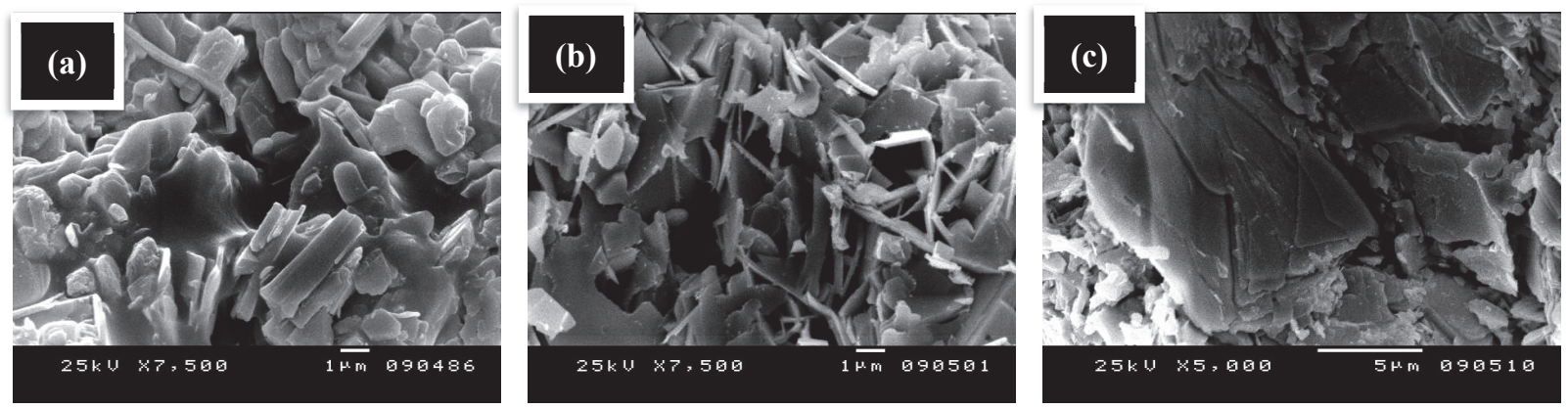

Figure 4. SEM micrographs of $\left(\mathrm{BaFe}_{12} \mathrm{O}_{19}\right)_{\mathrm{x}}(\mathrm{Bi}, \mathrm{Pb})-2223$ samples, for $\mathrm{x}=0.00(\mathrm{a}), \mathrm{x}=0.5 \%$ (b) and $1.5 \%(\mathrm{c})$. 


\subsection{Vickers Microhardness Measurements}

The experimental Vickers microhardness values $\mathrm{H}_{v}$ are calculated using Equation (2) and listed in Table 3. The variation of $\mathrm{H}_{\mathrm{v}}$ as function of the applied load $\mathrm{F}$ at $\mathrm{t}=30 \mathrm{sec}$ is shown in Figure 5. It is obvious that, $\mathrm{H}_{\mathrm{v}}$ decreases with a non-linear behavior with the increase of the applied load up to $2.96 \mathrm{~N}$, above which it reaches a saturation region and it becomes invariant with the load. This behavior is explained in terms of the penetration depth by Forester et al (Foerester et al, 2008); for small applied loads, surface layers are only affected, while for higher loads, the penetration reaches the inner layers where the response becomes ultimate.

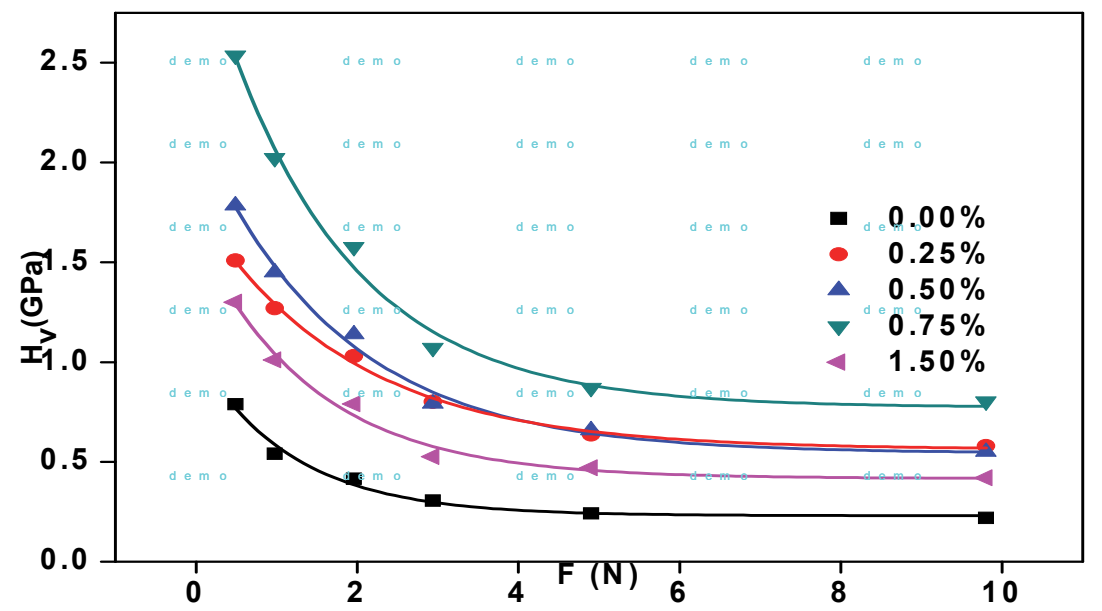

Figure 5. Variation of Vickers microhardness with the applied load at dwell time $\mathrm{t}=30 \mathrm{sec}$.

Moreover, it is observed that $\mathrm{H}_{\mathrm{v}}$ increases with increasing $\mathrm{BaFe}_{12} \mathrm{O}_{19}$ addition up to $\mathrm{x}=0.75$ wt. $\%$ and then decreases for higher addition $(\mathrm{x}=1.5 \mathrm{wt} . \%)$. Thus, nanoparticles addition has a significant effect in improving the microhardness of $(\mathrm{Bi}, \mathrm{Pb})-2223$ superconducting samples. This improvement is attributed to the reduction of porosity, enhancement of resistance and the increase in grain connectivity. This result is found to be consistent with SEM micrographs.

The ISE behavior is described by Meyer's law representing a relation between the applied load $F$ and the indentation diagonal:

$$
F=A d^{n}
$$

where $A$ is the standard microhardness constant and $\mathrm{n}$ is Meyer's index indicating the trend of the indentation size effect (ISE); for normal ISE, $\mathrm{n}<2$ and $\mathrm{H}_{\mathrm{v}}$ decreases as the applied load increases. Whereas for a reverse ISE, $\mathrm{n}>$ 2 and $\mathrm{H}_{\mathrm{v}}$ increases with the increase of the applied load. By plotting $\ln \mathrm{F}$ against $\ln \mathrm{d}$ in Figure 6, it is found that $\mathrm{n}$ $<2$ for all samples as listed in Table 3, verifying the observed normal ISE in Figure 5. Note that, the ceramic materials are characterized by their high microhardness, so, the values of $A_{1}$ are not acceptable to investigate the true microhardness of the samples. Thus, Meyer's law can only explain the ISE behavior of the data. Similar behavior was observed in $\mathrm{Bi}-\mathrm{Pb}-\mathrm{Sr}-\mathrm{Ca}-\mathrm{Cu}-\mathrm{O}$ phases [Murakami et al, 2002].

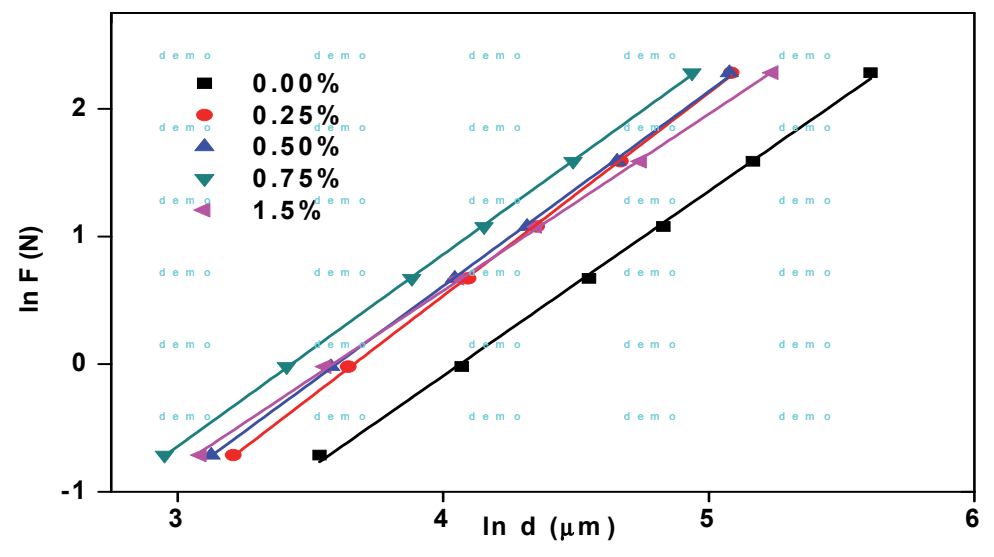

Figure 6. Variation of $\ln \mathrm{F}$ against $\ln \mathrm{d}$ at dwell time $\mathrm{t}=30 \mathrm{sec}$ 
In order to investigate the true microhardness of such materials, several models between the applied load and the indentation diagonal were considered to analyze the normal ISE.

Hays and Kendal's model (HK) (Hays, \& Kendall, 1975) proposed that plastic deformation is produced by a minimum applied load $\mathrm{W}$, so that:

$$
F=A_{1} d^{2}+W
$$

where $A_{1}$ is the HK load-independent microhardness constant, from which the corresponding load independent microhardness $H_{H K}$ is determined:

$$
H_{H K}=1854.4 \times A_{1}
$$

In Figure 7, $F$ is plotted against $d^{2}$ from which $W, A_{1}$ and $H_{H K}$ are determined and listed in Table 3 . The positive values of $W$ indicates that both elastic and plastic deformations are created by the load.

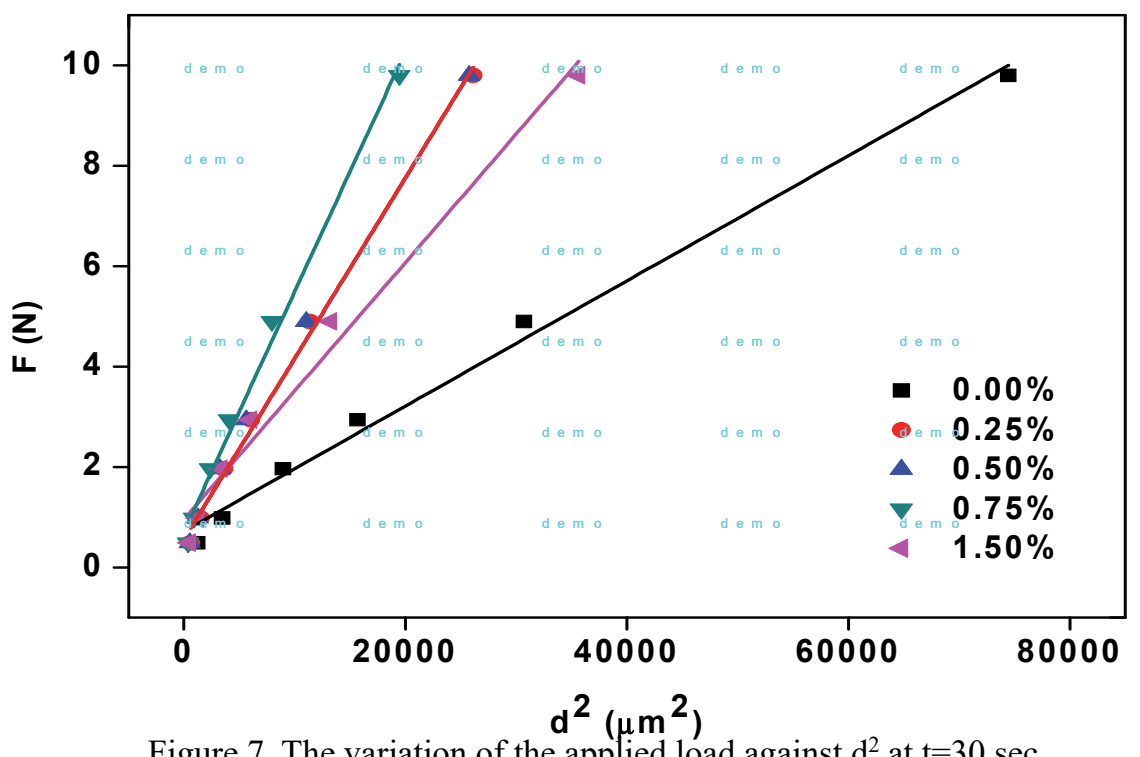

Figure 7. The variation of the applied load against $\mathrm{d}^{2}$ at $\mathrm{t}=30 \mathrm{sec}$.

Elastic-plastic deformation model (EPD) assumes that the indentation has an elastic deformation which tends to relax upon the removal of the load. So that, an elastic component $d^{\prime}$ is added to the indentation $d$ (Leenders, Ullrich, \& Freyhardt, 1997)(Li, Ghosh, \& Kobayashi, 1989):

$$
F=A_{2}\left(d+d^{\prime}\right)^{2}
$$

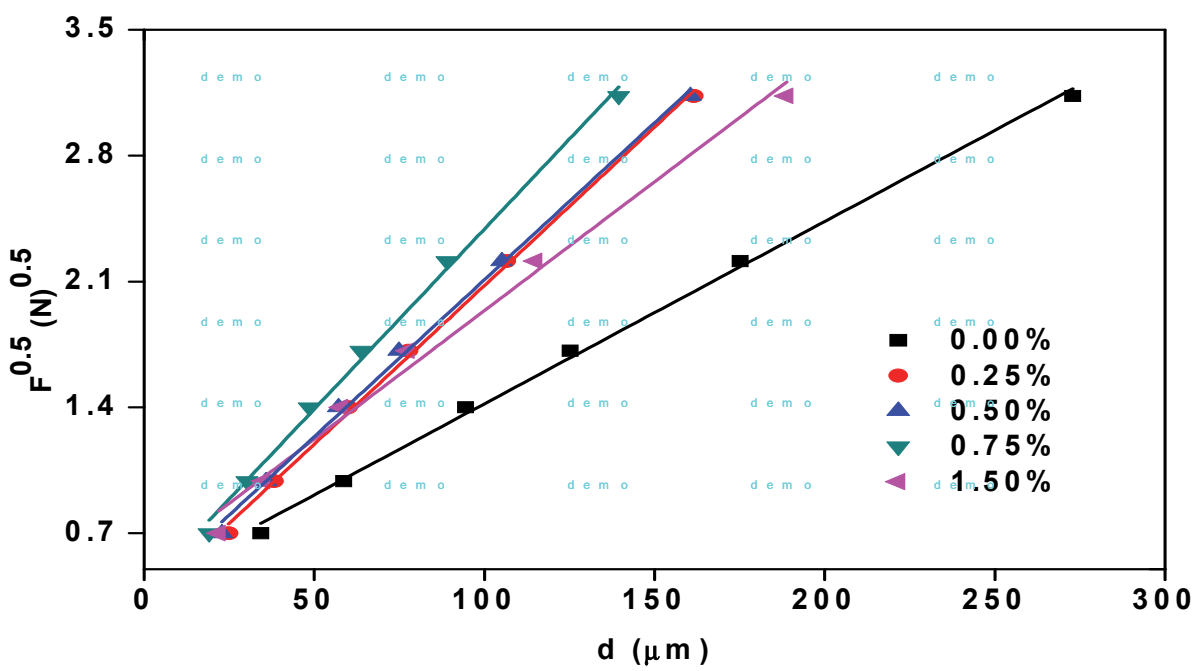

Figure 8 . The variation of $\mathrm{F}^{0.5}$ against $\mathrm{d}$ at dwell time $\mathrm{t}=30 \mathrm{sec}$. 
By plotting $F^{0.5}$ versus $d$ as seen in Figure 8, the constant $A_{2}$ and $d^{\prime}$ are determined and listed in Table 3 .

The elastic/plastic deformation load-independent microhardness, $H_{E P D}$, is calculated by the following relation:

$$
H_{E P D}=\mathrm{P} 854.4 \times A_{2}
$$

The positive values of $\mathrm{d}^{\prime}$ indicates that the elastic as well as the plastic deformations are present with an elastic relaxation for all samples.

By comparing the data in Table 3, it is clear that the results obtained from Hays and Kendal model are consistent with the experimental microhardness $\mathrm{H}_{\mathrm{v}}$ for our samples, with a relative error $<10 \%$. So, this model is suitable for describing the true microhardness of $\left(\mathrm{BaFe}_{12} \mathrm{O}_{19}\right) x(\mathrm{Bi}, \mathrm{Pb})-2223$ samples in the observed plateau region.

Table 3. Microhardness analysis results of different models for $\left(\mathrm{BaFe}_{12} \mathrm{O}_{19}\right) x(\mathrm{Bi}, \mathrm{Pb})-2223$ superconducting samples

\begin{tabular}{ccccccccccc}
\hline \multicolumn{3}{c}{ Meyer } & \multicolumn{4}{c}{$\mathrm{HK}$} \\
\hline $\begin{array}{c}\mathrm{x} \\
(\mathrm{wt} \%)\end{array}$ & $\begin{array}{c}\mathrm{H}_{\mathrm{v}} \\
(\mathrm{GPa})\end{array}$ & $\mathrm{n}$ & $\begin{array}{c}\mathrm{A}_{1} .10^{-4} \\
\left(\mathrm{~N} / \mu m^{2}\right)\end{array}$ & $\begin{array}{c}\mathrm{W} \\
(\mathrm{N})\end{array}$ & $\begin{array}{c}\mathrm{H}_{\mathrm{HK}} \\
(\mathrm{GPa})\end{array}$ & $\begin{array}{c}\text { Error } \\
(\%)\end{array}$ & $\begin{array}{c}\mathrm{A}_{2} .10^{-3} \\
\left(\mathrm{~N} / \mu m^{2}\right)\end{array}$ & $\begin{array}{c}\mathrm{d} \text { ( } \\
(\mu \mathrm{m})\end{array}$ & $\begin{array}{c}\mathrm{H}_{\mathrm{EPD}} \\
(\mathrm{GPa})\end{array}$ & $\begin{array}{c}\text { Error } \\
(\%)\end{array}$ \\
\hline 0.00 & 0.255 & 1.44 & 1.25 & 0.719 & 0.231 & 9.41 & 0.10 & 40.2 & 0.189 & 25.9 \\
0.25 & 0.673 & 1.59 & 3.60 & 0.564 & 0.667 & 0.85 & 0.32 & 17.8 & 0.574 & 14.6 \\
0.50 & 0.688 & 1.52 & 3.62 & 0.694 & 0.683 & 0.68 & 0.30 & 20.9 & 0.561 & 15.7 \\
0.75 & 0.893 & 1.50 & 4.78 & 0.718 & 0.886 & 1.32 & 0.40 & 19.5 & 0.741 & 17.4 \\
1.50 & 0.472 & 1.38 & 2.56 & 0.955 & 0.474 & 0.577 & 0.20 & 35.6 & 0.379 & 19.6 \\
\hline
\end{tabular}

The Vickers indentation can be used to evaluate some mechanical parameters such as elastic modulus $(\mathrm{E}=81.96 \mathrm{x}$ $\left.\mathrm{H}_{\mathrm{v}}\right)$ and yield strength $\left(\mathrm{Y}=\mathrm{H}_{\mathrm{v}} / 3\right)$. The obtained values of $\mathrm{E}$ and $\mathrm{Y}$ according to $\mathrm{HK}$ model, for $\left(\mathrm{BaFe}_{12} \mathrm{O}_{19}\right) \mathrm{x}(\mathrm{Bi}, \mathrm{Pb})-$ 2223, are listed in Table 4. It is observed that the elastic modulus and yield strength for ( $\mathrm{Bi}, \mathrm{Pb})-2223$ added by $\mathrm{BaFe}_{12} \mathrm{O}_{19}$ show an apparent increase with increasing $\mathrm{x}$ up to $0.75 \mathrm{wt} . \%$. Knowing that the elastic modulus is inversely proportional to the ductility, thus, higher nanoparticle concentration's samples have a higher ductility Terzioglu et al (Terzioglu, Varilci, \& Belenli, 2009) studied the effect of annealing temperature on mechanical properties of $\mathrm{MgB}_{2}$. They found that mechanical of the samples are improved with increasing annealing temperature from 650 to $850^{\circ} \mathrm{C}$ and they worsen at $950{ }^{\circ} \mathrm{C}$.

Table 4. Elastic modulus and yield strength of (BaFe12O19)x(Bi,Pb)-2223 superconducting samples.

\begin{tabular}{ccc}
\hline $\mathrm{x}(\mathrm{wt} . \%)$ & $\mathrm{E}(\mathrm{GPa})$ & $\mathrm{Y}(\mathrm{GPa})$ \\
\hline 0.00 & 18.93 & 0.077 \\
0.25 & 54.66 & 0.227 \\
0.50 & 55.97 & 0.227 \\
0.75 & 72.61 & 0.295 \\
1.50 & 38.84 & 0.158 \\
\hline
\end{tabular}

By evaluating the effect of dwell time in Figure 9, it is clear that $\mathrm{Hv}$ decreases with the increase of dwell time for $\mathrm{x}=0.00,0.75$ and $1.5 \%$ samples. It is clear that, at low dwell time the sharp time is transformed into linearity with increasing time. Such behavior is related to the bearing creep indentation (Zaki, et al, 2011). The power law indentation creep behavior is explained in term of indentation creep experiment at $0.49 \mathrm{~N}$ and $9.8 \mathrm{~N}$. Sargent and Ashby (Sargent \& Ashby, 1992) proposed an indentation creep's dimensional analysis:

$$
H(t)=\frac{\sigma_{0}}{\left(n c \sigma_{0} t\right)^{1 / \eta}} ?
$$

where $H(t)$ is the time dependent vickers microhardness, $\varepsilon_{0}$ is the strain rate at reference stress $r_{0}$ and $c$ is the constant. The slope of the $\ln (\mathrm{Hv})$ against $\ln t$, shown in Figure 10, is $(-1 / \eta)$, from which the value of the stress 
exponent $\eta$ is determined and listed in Table 5. The obtained lines are almost parallel indicating that $(\mathrm{Bi}, \mathrm{Pb})-2223$ superconductors are not affected by the addition of $\mathrm{BaFe}_{12} \mathrm{O}_{19}$.

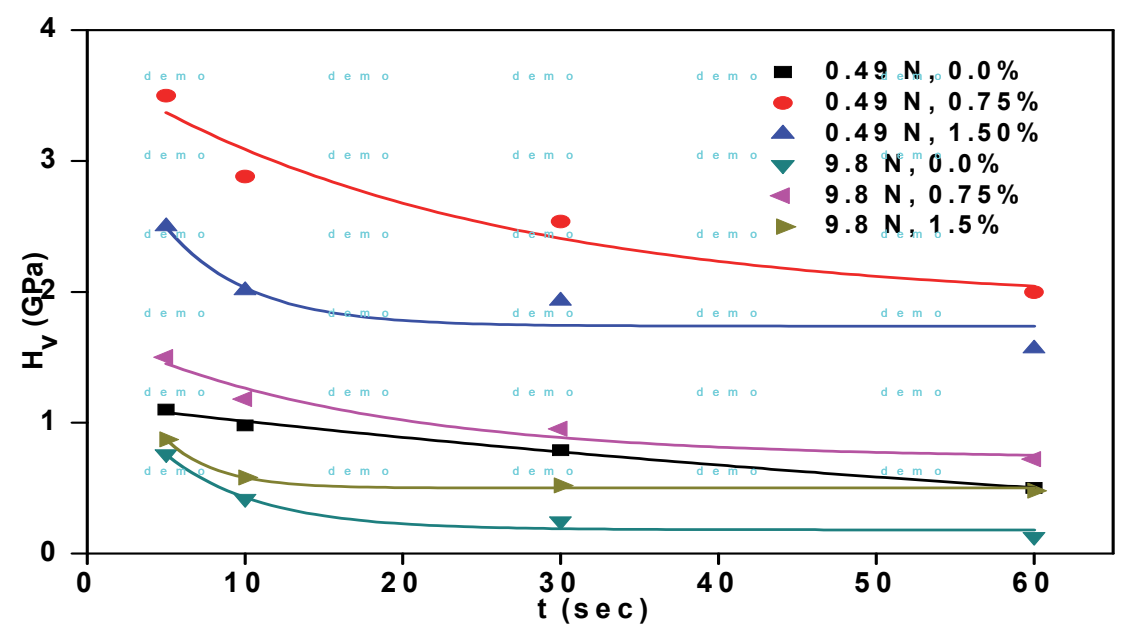

Figure 9. The variation of Vickers microhardness with dwell time at $\mathrm{F}=0.49 \mathrm{~N}$ and $\mathrm{F}=9.8 \mathrm{~N}$.

Table 5. Stress exponents for $\left(\mathrm{BaFe}_{12} \mathrm{O}_{19}\right)_{x}(\mathrm{Bi}, \mathrm{Pb})-2223$ superconducting $\quad$ at constant loads of $\mathrm{F}=0.49 \mathrm{~N}, \mathrm{~F}=2.49$ and $9.8 \mathrm{~N}$

\begin{tabular}{cccc}
\hline $\mathrm{x}$ & \multicolumn{3}{c}{$\eta$} \\
\cline { 2 - 4 } & $\mathrm{F}=0.49 \mathrm{~N}$ & $\mathrm{~F}=2.49 \mathrm{~N}=9.8 \mathrm{~N}$ \\
\hline 0.00 & 3.78 & 3.65 & 4.62 \\
0.75 & 5.98 & 3.58 & 3.58 \\
1.5 & 6.07 & 5 & 4.62 \\
\hline
\end{tabular}

It was reported by Goetze and Brace (Goetze \& Brace, 1972) and Kohlstedt and Goetze (Kohlstedt \& Goetze, 1974) that the dislocation creep dominates in the sample for a stress component lying between 3 and 10 . From Table 5, it is clear that the dislocation creep is the major mechanism operating in the samples with $3.65 \leq \eta \leq$ 6.07 .

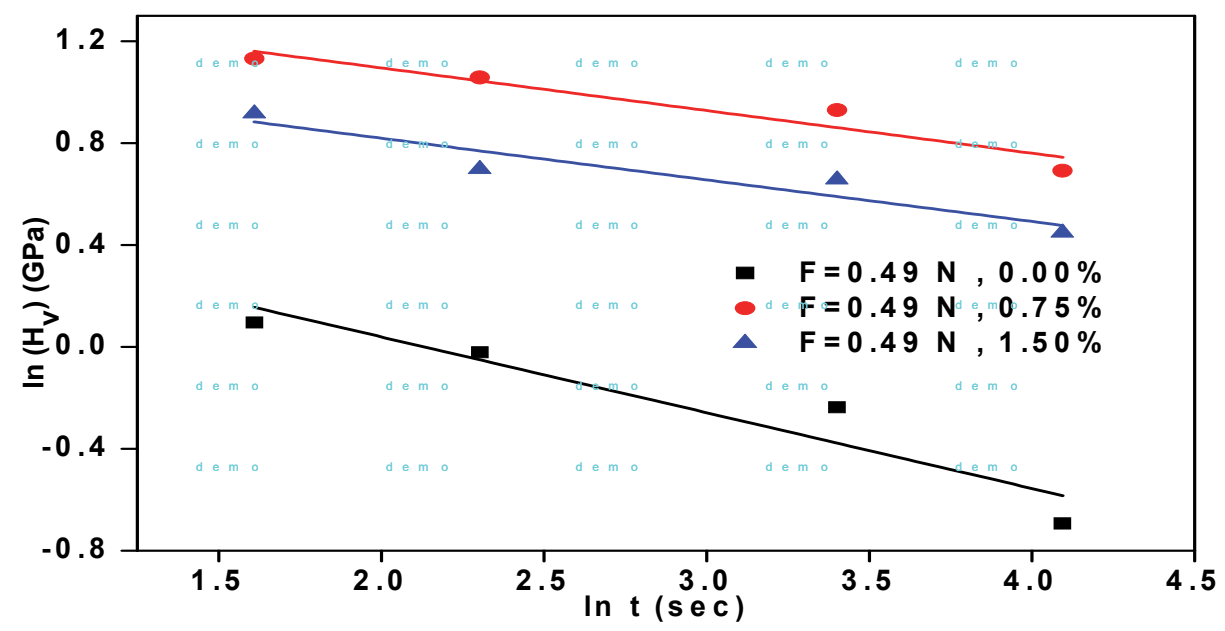

Figure 10. The variation of $\ln \mathrm{H}_{\mathrm{v}}$ against $\ln \mathrm{t}$ at $\mathrm{F}=0.49 \mathrm{~N}$.

\section{Conclusion}

As a summary, the addition of BaFe12O19 nanoparticles did not affect the structure of $(\mathrm{Bi}, \mathrm{Pb})-2223$ 
superconducting samples. They were settled at the boundaries where there was no change in the lattice parameters. Room temperature Vickers microhardness was studied as function of applied load, dwell time and BaFe12O19 addition. Vickers microhardness decreased with the applied load and time, whereas it increased with the nanoparticles addition up to $0.75 \%$ above which it decreased. This behavior was analyzed according to different models to investigate the true microhardness of the samples. Hays and Kendal model was the best in explaining the behavior of our studied samples in the plateau region with a relative error less than $10 \%$ rather than the elastic/plastic deformation. Stress exponent was calculated from the variation of Vickers microhardness as function of dwell time. The discolation creep is the operating creep in our samples, denoted by the calculated values of the stress exponent $\eta$.

\section{Acknowledgements}

This work was performed in the materials science lab, Faculty of Science, Beirut Arab University and EDSTPRASE, Lebanese University, Hadath in collaboration with The National Council for Scientific Research (CNRS), Lebanon.

\section{References}

Abdeen, W., Marhaba, S., Awad, R., Abou, Aly, A. I., Ibrahim, I. H., \& Matar, M. (2016). Electrical and mechanical properties of (Bi,Pb)-2223 substituted by holmium. Journal of Advanced Ceramics, 5(1), 54-69. https://doi.org/10.1007/s40145-015-0173-x.

Awad, R. (2008). Study of the Influence of MgO Nano-Oxide Addition on the Electrical and Mechanical Properties of (Cu0.25T10.75)-1234 Superconducting Phase. Journal of Superconductivity and Novel Magnetism, 21(8), 461-466. https://doi.org/10.1007/s10948-008-0385-1

Aydin, H., Cakiroglu, O., Nursoy, M., \& Terzioglu, C. (2009). Mechanical and superconducting properties of the Bi1.8Pb0.35Sr1.9Ca2.1Cu3 GdxOy system. Chinese Journal of Physics, 47(2), 192-206. 10.6122/CJP

Celebi, S., Karaca, I., Öztürk, A., \& Nezir. S. (1998). Fabrication and characterization of $\mathrm{Bi}_{1.84} \mathrm{~Pb}_{0.34} \mathrm{Sr}_{1.91} \mathrm{Ca}_{2.03} \mathrm{Cu}_{3.06} \mathrm{O}_{10}$ superconductors prepared by a wet technique. Journal of Alloys and Compounds, 268(1-2), 256-260.

Ding, J., Yang, H., Miao, W. F., McCormick, P. G., \& Street, R. (1995). High coercivity Ba hexaferrite prepared by mechanical alloying. Journal of Alloys and Compounds, 221(1-2), 70-73. https://doi.org/10.1016/09258388(94)01402-7

Foerster, C. E., Lima, E., Rodrigues, P. Jr., Serbena, F. C., Lepienski, C. M., Cantão, M. P., Jurelo, A. R., \& Obradors, X. (2008). Mechanical properties of Ag-doped top-seeded melt-grown YBCO pellets. Brazilian Journal of Physics, 38, 341. http://dx.doi.org/10.1590/S0103-97332008000300006.

Goetze, C., \& Brace, W. F. (1972). Laboratory observations of high-temperature rheology of rocks. Tectonophysics, 13(1-4), 583-600. https://doi.org/10.1016/0040-1951(72)90039-X.

Guilmeau, E., Andrzejewski, B., \& Noudem, J. G. (2003). The effect of MgO addition on the formation and the superconducting properties of the Bi2223 phase. Physica C: Superconductivity, 387(3-4), 382-390. https://doi.org/10.1016/S0921-4534(02)02360-2

Halim, S. A., Khawaldeh, S. A., Mohamed, S. B., \& Azhan, H. (1999). Superconducting properties of $\mathrm{Bi} 2-\mathrm{xPbxSr} 2 \mathrm{Ca} 2 \mathrm{Cu} 3 \mathrm{Oy}$ system derived via sol-gel and solid state routes. Materials Chemistry and Physics, 61(1), 251-259. https://doi.org/10.1016/S0254-0584(99)00164-9.

Haugan, T., Wong-Ng, W., Cook, L. P., Brown, H. J., Swartzendruber, L., \& Shaw, D. T. (2000). Flux pinning of $\mathrm{Bi} 2 \mathrm{Sr} 2 \mathrm{CaCu} 2 \mathrm{O} 8+\delta / \mathrm{Ag}$ superconductors utilizing $(\mathrm{Sr}, \mathrm{Ca}) 14 \mathrm{Cu} 24 \mathrm{O} 41$ defects and nanophase $\mathrm{A} 12 \mathrm{O} 3 \mathrm{and} \mathrm{Au}$ particles. Physica C: Superconductivity, 335(1-4), 129-133. https://doi.org/10.1016/S0921-4534(00)00157$\mathrm{X}$

Hays, C., \& Kendall, E. G. (1973). An analysis of Knoop microhardness. Metallography, 6(4), $275-282$. https://doi.org/10.1016/0026-0800(73)90053-0

Ishizuka, M., \& Sakabura, J. (2006). Critical current density (Jc) and mechanical characteristics of a Bi-2223 bulk current lead for cryocooler-cooled superconducting magnets. Physica C: Superconducivity, 433(3-4), 173181. https://doi.org/10.1016/j.physc.2005.10.012

Jia, Z. Y., Tang, H., Yang, Z. Q., Xing, Y. T., Wang, Y. Z., \& Qiao, G. W. (2000). Effects of nano-ZrO2 particles on the superconductivity of Pb-doped BSCCO. Physica C: Superconductivity, 337(1-4), 130-132. https://doi.org/10.1016/S0921-4534(00)00072-1 
Karaca, I., Uzun, O., Kolemen, U., Yılmaz, F., \& Sahin, O. (2009). Effects of ZnO addition on mechanical properties of $\mathrm{Bi}_{1.84} \mathrm{~Pb}_{0.34} \mathrm{Sr}_{1.91} \mathrm{Ca}_{2.03} \mathrm{Cu}_{3.06} \mathrm{O}_{10}$ prepared by a wet technique. Journal of Alloys and Compounds, 476(1-2), 486-491. https://doi.org/10.1016/j.jallcom.2008.09.077

Kazin, P. E., Jansen, M., Larrea, A., de la Fuente, G. F., \& Tretyakov, Yu. D. (1995). Flux pinning improvement in $\mathrm{Bi} 2212$ silver sheathed tapes with submicron $\mathrm{SrZrO3}$ inclusions. Physica C: Superconductivity, 253(3-4), 391-400. https://doi.org/10.1016/0921-4534(95)00504-8

Khalil, S. M. (2006). Effect of Cd Addition on Superconducting Fluctuations and Mechanical Properties of $\mathrm{Bi}_{1.82} \mathrm{~Pb}_{0.36} \mathrm{Sr}_{2} \mathrm{Ca}_{2} \mathrm{Cd}{ }_{x} \mathrm{Cu}_{3} \mathrm{O}$ y System. Journal of Low Temperature Physics, 143(1-2), 31-44. https://doi.org/10.1007/s10909-006-9209-5.

Kohlstedt, D. L., \& Goetze, C. (1974). Low-stress high-temperature creep in olivine single crystals. Journal of Geophysical Research, 79(14), 2045-2051. https://doi.org/10.1029/JB079i014p02045

Kolemen, U., Uzun, O., Yilmazlar, M., Guclu, N., \& Yanmaz, E. (2006). Hardness and microstructural analysis of Bi1.6Pb0.4 $\mathrm{Sr} 2 \mathrm{Ca} 2-\mathrm{xSmxCu} 3 \mathrm{Oy}$ polycrystalline superconductors. Journal of Alloys and Compounds, 415(1-2), 300-306. https://doi.org/10.1016/j.jallcom.2005.09.023

Kong, W., \& Abd-Shukor, R. (2010). Enhanced Electrical Transport Properties of Nnao NiFe2O-added (Bi1.6Pb0.4)Sr2Ca2Cu3O10 superconductor. Journal of superconductivity and Novel Magnetism, 23(2), 257. https://doi.org/10.1007/s10948-009-0524-3

Konishi, H., Takamura, T., Kaga, H., \& Katsuse, K. (1989). A New Fabrication Process for High- $T_{\mathrm{c}}$ Superconducting Oxide Ceramic Fibers. Japanese Journal of Applied Physics, 28, 241-243. https://doi.org/10.1143/JJAP.28.L241

Leenders, A., Ullrich, M., \& Freyhardt, H. C. (1997). Influence of thermal cycling on the mechanical properties of VGF melt-textured YBCO, Physica C: Superconductivity, 279(3-4), 173-180. https://doi.org/10.1016/S0921-4534(97)00132-9 .

Li, S., Gao, W., Cooper, H., Liu, H. K., \&. Dou, S. X. (2001). The effect of mechanical deformation on the phase transformation of BSCCO superconductors. Physica C: Superconductivity, 356(3), 197-204. https://doi.org/10.1016/S0921-4534(01)00161-7

Li, Z., Ghosh, A., \& Kobayashi, A. S. (1989). Indentation Fracture Toughness of Sintered Silicon Carbide in the Palmqvist Crack Regime. Journal of the American Ceramic Society, 72(6), 904-911. https://doi.org/10.1111/j.1151-2916.1989.tb06242.x

Mohammed, N. H., Abou-Aly, A. I., Ibrahim, I. H., Awad, R., \& Rekaby, M. (2011). Effect of Nano-Oxides Addition on the Mechanical Properties of $\left(\mathrm{Cu}_{0.5} \mathrm{Tl}_{0.5}\right)-1223$ Phase. Journal of Superconductivity and Novel Magnetism, 24(5), 1463-1472. https://doi.org/10.1007/s10948-010-0853-2.

Murakami, A., Katagari, K., Noto, K., Kasaba, K., Sohoji, Y., Muralidhar, M., Sakai, N., \& Murakami, M. (2002). Tensile mechanical properties of ( $\mathrm{Nd}, \mathrm{Eu}, \mathrm{Gd})-\mathrm{Ba}-\mathrm{Cu}-\mathrm{O}$ bulk superconductors at room and liquid nitrogen temperatures. Physica C: Superconductivity, 378-381, 794-797. https://doi.org/10.1016/S09214534(02)01545-9.

Ohlan, A., Singh, K., Chandra, A., \& Dhawan, S. K. (2008). Microwave absorption properties of polymer composite with barium ferrite nanoparticles in 12.4-18 GHz. Applied Physics letters, 93, 053114. https://doi.org/10.1063/1.2969400

Sargent, P. M., \& Ashby, M. F. (1992). Indentation creep, Materials Science and Technology, 8(7), 549-601. https://doi.org/10.1179/mst.1992.8.7.594.

Sengupta, S., Todt, V. R., Kostic, P., Chen, Y. L., Lanagan, M. T., \& Goretta, K. C. (1996). Flux pinning in TlBa2Ca2Cu3Ox through addition of nanophase Al2O3. Physica C: Superconductivity, 264(1-2), 34-42. https://doi.org/10.1016/0921-4534(96)00191-8

Terzioglu, C. (2011). Investigation of some physical properties of Gd added Bi-2223 superconductors. Journal of Alloys and Compounds, 509(1), 87-93. https://doi.org/10.1016/j.jallcom.2010.08.105

Terzioglu, C., Varilci, A., \& Belenli, I. (2009). Investigation of effect of annealing temperature on mechanical properties of MgB2. Journal of Alloys and Compounds, 478(1-2), 836-841. https://doi.org/10.1016/j.jallcom.2008.12.044 
Yilmazlar, M., Centinkara, H. A., Nursoy, M., Ozturk, O., \& Terzioglu, C. (2006). Thermal expansion and Vickers hardness measurements on $\mathrm{Bi1} .6 \mathrm{~Pb} 0.4 \mathrm{Sr} 2 \mathrm{Ca} 2-\mathrm{xSmxCu} 3 \mathrm{Oy}$ superconductors. Physica C: Superconductivity, 442(2), 101-107. https://doi.org/10.1016/j.physc.2006.04.093

Zaki, H. M., Abdel-Daiem, A. M., Swilem, Y. I., El-Tantawy, F., Al- Marzouki, F. M., Al-Ghamdi, A. A., \& AlHarbi, T. S. (2011). Materials Science and Applications, 2, 1076-1082. https://doi.org/10.4236/msa.2011.28145

\section{Copyrights}

Copyright for this article is retained by the author(s), with first publication rights granted to the journal.

This is an open-access article distributed under the terms and conditions of the Creative Commons Attribution license (http://creativecommons.org/licenses/by/4.0/). 